\title{
CORRIGENDUM
}

\section{Assessment of cardiovascular reactivity by fractal and recurrence quantification analysis of heart rate and pulse transit time}

JE Naschitz, R Itzhak, N Shaviv, I Khorshidi, S Sundick, H Isseroff, M Fields, RM Priselac, D Yeshurun and E Sabo

Journal of Human Hypertension (2003) 17, 585. doi:10.1038/sj.jhh.1001615

Correction to: Journal of Human Hypertension 2003; 17: 111-118. doi: 10.1038/sj.jhh.1001517

In the above paper, an error has been identified in the listing of an author's name. The second author listed should be Itzak Rosner, and therefore should appear as:

I Rosner 